\title{
Alternative Drug Delivery for Patients Undergoing Cataract Surgery as Demonstrated in a Canine Model
}

\author{
L. David Waterbury
}

\begin{abstract}
Purpose: (1) To determine ketorolac concentrations in selected ocular tissues following the intracameral administration of phenylephrine and ketorolac injection $1 \% / 0.3 \%\left(\right.$ OMIDRIA $\left.^{\circledR}\right)$ delivered in irrigation solution during lens replacement surgery in beagle dogs. (2) To compare the ketorolac initial dose and resultant concentrations from the above study to those achieved in aqueous and vitreous by topical administration in patients undergoing cataract surgery or vitrectomy, respectively.

Methods: Lens replacement surgery with phacoemulsification was performed in 20 female beagle dogs. A fixed combination of phenylephrine and ketorolac injection $1 \% / 0.3 \%$ was diluted 125 -fold into the balanced salt solution and delivered intracamerally during the phacoemulsification procedure. Ketorolac concentration was determined by liquid chromatography/mass spectrometry.

Results: Concentrations of ketorolac when administered by the intracameral route in the dosing solution in dogs were found to be considerably higher in both aqueous and vitreous compared to what is achieved with topical dosing in patients.

Conclusions: Adequate therapeutic concentrations of ketorolac in aqueous and vitreous humor were achieved even at $10 \mathrm{~h}$ postdose. Critical concentrations in the aqueous that envelopes the iris/ciliary body, which are sites of prostaglandin $\mathrm{E}_{2}$ synthesis, and the vitreous are not achieved by topical dosing in clinical studies after the surgery, but are by direct intracameral dosing as determined in this study. Based on these studies and clinical data, phenylephrine and ketorolac injection 1\%/0.3\% delivered during surgery as an irrigation solution may preclude the need for topically administered pre- and postoperative NSAIDs.
\end{abstract}

Keywords: cataract surgery, NSAIDs, ketorolac, anti-inflammatory, topical dosing

\section{Introduction}

W HILE CATARACT SURGERY has made many technical advances over the past 20 years, ${ }^{1-3}$ the administration of ophthalmic drugs accompanying the surgery remains reliant on topical drug delivery, which has changed little for several decades. Dosing topically multiple times before cataract surgery with nonsteroidal anti-inflammatory drugs (NSAIDs) or corticosteroids has become very commonplace. ${ }^{4-6}$ The purpose of the present study was to compare the ketorolac total dose and concentrations in ocular tissues achieved utilizing an intracameral administration of phenylephrine (PE) and ketorolac (KE) injection $1 \% / 0.3 \%$ diluted in buffer solution in a canine model of lens replacement surgery with those achieved by topical dosing in human cataract surgery and also from patients undergoing vitrectomies. A preliminary report with some of these findings was recently published. ${ }^{7}$ The available tissues common to animal and human clinical studies are aqueous and vitreous humors. Phenylephrine concentrations were not determined in this study because comparable clinical samples were not available. Likewise, sampling times were limited to correspond to the availability of clinical samples. While it is recognized that dog ocular pharmacokinetics may differ in significant ways to that of humans, this study does raise questions about the usefulness of topical dosing of NSAIDs before cataract surgery, particularly when intraoperative administration is available.

Raven Biosolutions LLC, San Carlos, California.

(C) L. David Waterbury 2018; Published by Mary Ann Liebert, Inc. This is an Open Access article distributed under the terms of the Creative Commons Attribution License, which permits unrestricted use, distribution, and reproduction in any medium, provided the original work is properly cited. 


\section{Methods}

\section{Canine studies}

This study was conducted in adherence to the ARVO Statement on the Use of Animals in Ophthalmic and Vision Research. All of the dog studies were conducted at Covance, Madison, Wisconsin, and were approved by the Covance Institutional Review Board. The dog was chosen for this study because of the availability of replacement lenses, and the absence of fibrin aggregates commonly seen in rabbits. ${ }^{8}$ In addition, the retinal circulation and anatomy in dogs more closely resembled that of humans with some notable exceptions such as the presence of a tapetum. ${ }^{9}$

Preoperative treatment and surgery were performed as previously described. ${ }^{10}$ Twenty female beagle dogs were used in the experiments following an acclimation period of 11 days. Animals were between 8 and 9 months of age and of similar size. All animals were found to have normal ophthalmic examinations before the study.

\section{Surgical procedure}

Following an overnight fast, dogs were treated preoperatively with one topical drop of $1 \%$ tropicamide, $2.5 \%$ phenylephrine, and an antibiotic solution every few minutes for a total of 4 doses. Additional topical drops of tropicamide were administered to maintain pupil dilation as needed. Dogs were given an intravenous injection of dexamethasone $(0.1 \mathrm{mg} / \mathrm{kg})$ and oxymorphone $(0.2 \mathrm{mg} / \mathrm{kg})$. Anesthesia was provided by an intravenous injection of dexmedetomidine (0.01- $0.02 \mathrm{mg} / \mathrm{mg}$ ) followed by intubation. Sevoflurane with oxygen was used as an inhalant for anesthesia. The eyes of each animal were treated with a solution of $1 \%$ povidoneiodine $/ 5 \%$ betadine for ophthalmic use.

Intraocular lens replacement was performed on the right eye of each animal by a veterinary ophthalmologist. Following a corneal incision, aqueous humor was exchanged for $1 \%$ sodium hyaluronate, and an anterior capsular flap was created. The lens was extracted by phacoemulsification followed by irrigation and aspiration of the lens cortex using $4 \mathrm{~mL}$ of phenylephrine and ketorolac injection $1 \% / 0.3 \%$ $\left(\text { OMIDRIA }^{\circledR}\right)^{11}$ diluted into $500 \mathrm{~mL}$ of balanced salt solution (BSS; McKesson, GA). After dilution in BSS, the administered concentrations were $0.008 \%$ phenylephrine and $0.00024 \%$ ketorolac.

The lens capsule was filled with viscoelastic and a foldable acrylic dog-specific lens (DIOP, Dioptrix, France), which was allowed to unfold. The corneal incision was closed, and any remaining viscoelastic removed by irrigation and aspiration using the above diluted irrigation solution. The anterior chamber was reinflated by an injection of up to $1 \mathrm{~mL}$ of diluted $\left(\right.$ OMIDRIA $\left.^{\circledR}\right)$ /BSS. In addition, the diluted irrigation solution was used for corneal hydration throughout the procedure. The total surgery time ranged from 19 to $39 \mathrm{~min}$.

\section{Sample collection}

Due to the nature of phenylephrine and ketorolac injection $1.0 \% / 0.3 \%$ in BSS administration as an irrigation solution, a rinse solution, and for corneal hydration, the method used to estimate the total drug delivered during the procedure was as follows: ocular tissues, aqueous, cornea, iris/ciliary body, lens capsule, palpebral conjunctiva, bulbar conjunctiva, vitreous, anterior and posterior sclera, vitreous, retina, retinal choroid/ retinal pigment epithelium (RPE), and plasma samples were collected immediately after the surgical procedure (time 0 ), and at 2, 6, 8, and $10 \mathrm{~h}$ postoperatively. Aqueous samples were obtained using a syringe and samples were frozen. This was followed by the removal of the entire right eye, which was then frozen in liquid nitrogen. Within 3 days, all of the samples listed above were obtained, rinsed, blotted, and refrozen until analysis.

For each of the tissues listed above, an estimate of the initial dose of ketorolac was achieved by determining the concentration of ketorolac in each, then multiplying the concentrations by the corresponding individual tissue weights and summing those values. The total plasma amount for each dog was derived by multiplying the measured plasma concentration by the published plasma volume ${ }^{12}$ again multiplying that amount by the animal weight for each dog in $\mathrm{kg}$. A similar methodology as described above was used to determine ocular tissue distribution at all remaining time points (ie, $2,6,8$, and $10 \mathrm{~h}$ postoperatively).

\section{Sample analysis}

Ketorolac concentrations in aqueous humor and vitreous were determined by protein precipitation in methanol, water (1:1), and then ascertained using liquid chromatography/ mass spectrometry. Ocular tissue samples were homogenized in methanol/water $(1: 1)$ and extracted by $0.05 \%$ formic acid in methyl tert-butyl ether. Control solutions of ketorolac- $\mathrm{d} 4$, were used as an internal standard. Samples were mixed by vortex and centrifuged for $5 \mathrm{~min}$ at 2,500 rpms. The supernatant extracts were transferred and dried to completeness under a stream of nitrogen gas.

The resulting residue was reconstituted in 60:40:0.05 water:methanol:formic acid. Samples were stored in a chilled autosampler until analysis. The mobile phase A consisted of $0.1 \%$ formic acid in 5\% methanol:95\% water. The mobile phase B consisted of $0.1 \%$ formic acid in methanol. A Waters X-bridge C18 column $(50 \mathrm{~mm} \times 2.1 \mathrm{~mm} \times 3.5 \mu \mathrm{m})$ was used in line with a Phenomenex C18 SecurityGuard cartridge $(4 \times 2 \mathrm{~mm})$, heated to $30^{\circ} \mathrm{C}$. Initial conditions were held at $35 \%$ mobile phase $\mathrm{B}$ for $1 \mathrm{~min}$ following sample injections. A linear gradient was applied to increase mobile phase B to $95 \%$ over the next 2 min, followed by a hold and equilibration time at a rate of $0.5 \mathrm{~mL} /$ min. The total run time of the assay was less than 5 min.

The fragment ions, ketorolac $(\mathrm{m} / \mathrm{z}, 256.1 / \mathrm{m} / \mathrm{z}, 105.0)$ and ketorolac-d4 ( $/ 2 / z, 260.2 / m / z, 104.9)$, were detected by multiple reaction-monitoring MS/MS using characteristic fragmentation of each ion resulting from collision-induced dissociation. The instrument used was a Sciex API-4000 QTrap, set to positive electrospray ionization with an ion spray voltage of $5,000 \mathrm{~V}$ and gas temperature of $550^{\circ} \mathrm{C}$. The dwell time that the instrument scans for each ion was set at $200 \mathrm{~ms} / \mathrm{ion}$ for each cycle. The retention time for both samples on the HPLC column was $\sim 2.81 \mathrm{~min}$. Biofluid and tissue calibration ranges were from 2.5 to $5,000 \mathrm{ng} / \mathrm{mL}$ in solvent extracts. Levels of the ketorolac were calculated in the extract fluids as ng/mL. Following analysis, the tissue concentrations were back-calculated to $\mathrm{ng} / \mathrm{g}$ values accounting for the tissue weights of each sample. Calibration standards were derived from multiple processed tissues, and therefore, an average tissue weight was used in the calculation of ketorolac levels in calibration standards. 
Table 1. Tissue Weights and Total Dose in Plasma and Ocular Tissues at Time 0

\begin{tabular}{llcrr}
\hline & \multicolumn{1}{c}{ Tissue } & $\begin{array}{c}\text { Mean weight } \\
m g(m L) \pm S E M\end{array}$ & $\begin{array}{r}\text { Tissue concentration } \\
\mu g / g(m L) \pm S E M\end{array}$ & $\begin{array}{r}\text { Total dose } \\
(\mu g) \pm S E M\end{array}$ \\
\hline Anterior segment & Aqueous & $0.429 \pm 0.066$ & $16.80 \pm 0.47$ & $7.26 \pm 0.202$ \\
& Cornea & $0.122 \pm 0.003$ & $2.86 \pm 0.05$ & $0.35 \pm 0.006$ \\
& Conjunctiva & $0.119 \pm 0.009$ & $1.37 \pm 0.41$ & $0.076 \pm 0.041$ \\
& Iris/ciliary body & $0.130 \pm 0.012$ & $2.81 \pm 0.42$ & $0.36 \pm 0.055$ \\
& Anterior sclera & $0.285 \pm 0.016$ & $1.05 \pm 0.091$ & $0.30 \pm 0.026$ \\
& Lens capsule & $0.013 \pm 0.002$ & $1.41 \pm 0.41$ & $0.019 \pm 0.005$ \\
Posterior segment & Total... & - & & $8.37 \pm 0.34$ \\
& Retina & $0.059 \pm 0.001$ & $1.83 \pm 0.36$ & $0.11 \pm 0.02$ \\
& Vitreous & $1.90 \pm 0.06$ & $1.13 \pm 0.37$ & $2.13 \pm 0.71$ \\
& Choroid/RPE & $0.080 \pm 0.002$ & $1.59 \pm 0.05$ & $0.15 \pm 0.02$ \\
Plasma & Posterior sclera & $0.252 \pm 0.011$ & $0.64 \pm 0.16$ & $0.16 \pm 0.04$ \\
Total ketorolac & Total.... & & & $2.55 \pm 0.79$ \\
& & 379.0 & $0.00470 \pm 0.00073$ & $1.78 \pm 0.28$ \\
\hline
\end{tabular}

SEM, standard error of the mean.

\section{All data were analyzed with Analyst ${ }^{\circledR} 1.5 .1$ software}

Ketorolac concentrations are reported as mean \pm standard error of the mean (SEM) in $\mathrm{ng} / \mathrm{mL}$. All values in this study were above the limits of detection $(2.5 \mathrm{ng} / \mathrm{mL})$. The values obtained were compared with published values for the $\mathrm{IC}_{50}$ values against human recombinant $\mathrm{COX}-1$ and $\mathrm{COX}-2$ enzymes. ${ }^{13}$ Estimates of the Ki were calculated followed by estimations of $90 \%$ inhibition. Note that these are human recombinant $\mathrm{COX}-1$ and $\mathrm{COX}-2$ values and not canine COX-1 and COX-2 inhibition results, which may be very different. To compare the above values with those reported by Katsev et al., ${ }^{14}$ values in this study identified as below $1 \mathrm{ng} / \mathrm{mL}$ (below limits of detection) were divided by 2 to obtain a mean \pm SEM. ${ }^{15}$ In some cases where literature values were followed by standard deviation of the mean, these were recalculated as SEMs for consistency.

\section{Results}

Table 1 shows the mean weights/volumes, \pm SEMs of dog ocular tissues along with the concentrations \pm SEMs, and calculated total amount of ketorolac in each tissue separated out into the anterior and posterior segments immediately after lens replacement surgery (time 0). This table shows the means of 4 determinations where individual weights were multiplied times ketorolac concentrations $(n=4)$. The total plasma amount of ketorolac was obtained by multiplying the published plasma volume of drugs by the body weight in kilogram ${ }^{12}$ times the mean plasma concentration at time 0 . The summed total gives an estimate of the total dose delivered by a formulation of ketorolac $(0.0024 \%)$ and phenylephrine $(0.008 \%)$ as diluted in irrigation solu- tion. The total estimated dose was $12.70 \mu \mathrm{g}$. The highest total amounts of ketorolac are found in the aqueous and vitreous. In the vitreous, it is likely due to the total greater mass of this tissue.

The plasma concentration of ketorolac in the canine study immediately after surgery was determined to be $4.70 \pm 0.73$ SEM ng/mL (Table 2). This value is somewhat higher than the amount in plasma reported in a clinical study ${ }^{11}$ of $1.0-$ $4.2 \mathrm{ng} / \mathrm{mL}$. The lower limits of detection were not stated for this study. However, if the amount present in plasma is estimated reflecting the differences in dog vs. human plasma volumes, the estimated concentration would be $1.65 \mathrm{ng} / \mathrm{mL}$, which is in line with the findings of that clinical study.

These findings suggest that higher plasma levels (11$23 \mathrm{ng} / \mathrm{mL}$ in $8 / 28$ patients) observed ${ }^{16}$ may be associated with topical dosing. The lower limits of detection were not identified in the above source.

At $2 \mathrm{~h}$ postsurgery, plasma levels of ketorolac were undetectable in 14 of 16 animals. This suggests that absorption into the systemic circulation occurred during the initial dosing procedure. Further analysis of the tissue distribution indicated that the largest percentage of dosed ketorolac was located in the anterior segment at initial time points.

The total ketorolac, as well as that contained in aqueous, iris/ciliary body, vitreous, retina, and choroid/RPE tissues are shown graphically in Fig. 1 over the 10-h time course. After a rapid drop in ketorolac levels over the first $2 \mathrm{~h}$, ketorolac levels continued to decline, but at a slower rate. Ketorolac concentrations were sufficient to inhibit both COX-1 and COX-2 (human recombinant results ${ }^{13}$ ) in all tissues and at all time points studied.

Aqueous concentrations of ketorolac are shown in Fig. 2 by intracameral dosing of phenylephrine/ketorolac with lens

Table 2. Plasma levels Following Topical and Intracameral Administration of Ketorolac as an IRRIGATION SOLUTION

\begin{tabular}{llcc}
\hline Drug tested & Species & Determined & Ketorolac $($ ng/mL) \\
\hline Intracameral irrigation solution phenylephrine+ketorolac & Canine & $4 / 4$ & $4.70(1.65)^{\mathrm{a}}$ \\
Intracameral irrigation solution phenylephrine+ketorolac & Human & $10 / 14^{11}$ & $1.0-4.2$ \\
$0.5 \%$ Ketorolac topical & Human & $8 / 28^{16}$ & $11-23$ \\
\hline
\end{tabular}

${ }^{\mathrm{a}}$ Value in parenthesis estimated using human plasma volume. 


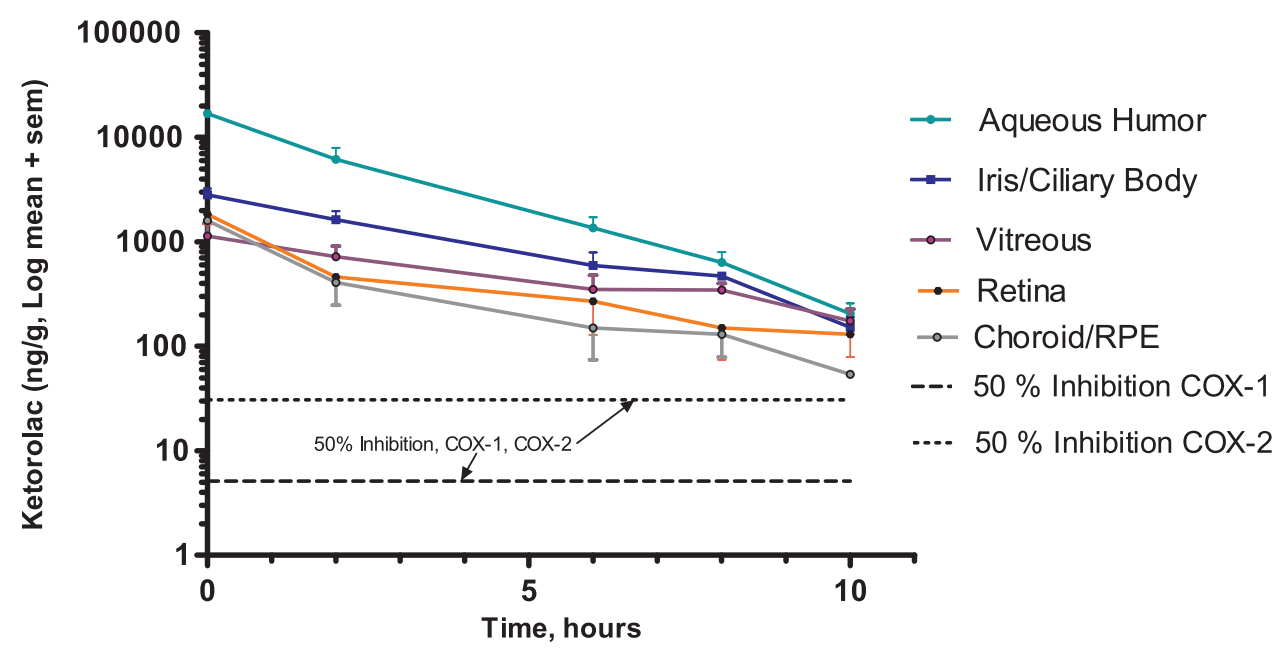

FIG. 1. Decline of ketorolac over a 10-h period after intracameral dosing with phenylephrine/ketorolac delivered in irrigation solution in lens replacement surgery in dogs. This figure shows the ketorolac concentration in ng \pm SEMs at $0,2,6$, 8 , and $10 \mathrm{~h}$ of aqueous, iris/ciliary body, vitreous, choroid/RPE, and retina following lens implantation surgery in dogs after dosing with phenylephrine/ketorolac, delivered in irrigation solution. The final concentrations were $0.008 \%$ phenylephrine and $0.00024 \%$ ketorolac. In addition, the concentrations required to inhibit COX-1 and COX-2 by $50 \%$ are shown based on results using human recombinant COX-1 and COX-2. ${ }^{13}$ This suggests that sufficient levels of ketorolac are present in these tissues to inhibit both isoforms of COX-1 and COX-2 at time points studied. RPE, retinal pigment epithelium; SEM, standard error of the mean.

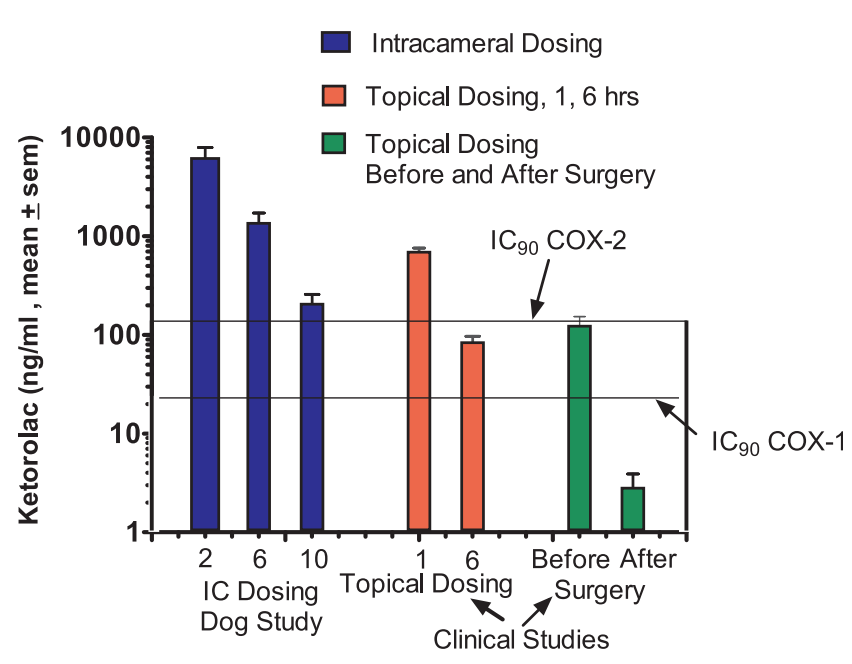

FIG. 2. Ketorolac concentrations in aqueous humor at 2, 6 , and $10 \mathrm{~h}$ after dosing with $0.008 \%$ phenylephrine and $0.00024 \%$ ketorolac compared with topical dosing. This figure shows concentrations of aqueous humor expressed as mean $\mathrm{ng} / \mathrm{mL} \pm \mathrm{SEM}$ for time points $2,6,8$, and $10 \mathrm{~h}$ after lens implantation surgery in dogs (4 samples/time point) using $0.008 \%$ phenylephrine and $0.00024 \%$ ketorolac delivered intracamerally through the irrigation solution. The next set of values (red bars) shows topical dosing (clinical study) at 1 and $6 \mathrm{~h}$ after dosing. This results in adequate concentrations to completely inhibit COX-1 (>90\% inhibition) at these time points. As shown (green bars), topical dosing also achieves adequate aqueous levels before surgery. However, determinations with topical dosing followed by cataract surgery revealed a substantial loss of ketorolac, which was insufficient to inhibit COX-1 or COX-2 $2^{13,14}$ (human recombinant COX-1 and COX-2) bringing into question whether this is reflected in tissue levels such as in the iris/ciliary body as well. implant surgery, and compared with those achieved by topical dosing in human subjects. At all measured time points, concentrations of ketorolac in the aqueous by intracameral dosing were in excess of that required for $90 \%$ inhibition of both COX-1 and COX-2. ${ }^{13}$ Effective concentrations of ketorolac in the aqueous were also achieved by topical dosing.

The center graph shows concentrations achieved by 2 dosing regimens. Patients in the 1 -h time point self-dosed $0.45 \%$ ketorolac BID 1 day before surgery, and the morning of the surgery. This was followed by 4 additional doses $1 \mathrm{~h}$ before the surgery. ${ }^{17}$ Concentrations achieved in this study are similar to those achieved at $6 \mathrm{~h}$ following intracameral administration. Topical dosing of ketorolac $0.40 \%$ at $6 \mathrm{~h}$ before surgery resulted in a considerably lower concentration of ketorolac in aqueous ${ }^{18}$ compared with results achieved by intracameral dosing.

The last panel shows the before and after concentrations of ketorolac associated with cataract surgery. ${ }^{14}$ Following surgery, ketorolac levels are significantly reduced and do not provide sufficient concentrations to significantly inhibit COX-1 or COX-2. In contrast, substantial levels of ketorolac are evident at even $10 \mathrm{~h}$ after intracameral dosing in the aqueous $(205 \pm 52 \mathrm{ng} / \mathrm{mL}$, mean \pm SEM $)$-levels sufficient to inhibit prostaglandin synthesis.

To address the question of whether topical dosing of NSAIDs reaches therapeutic concentrations in the posterior segment, a comparison was made between vitreous levels after intracameral dosing with lens implant surgery at 2, 6, and $10 \mathrm{~h}$ with those levels detected in vitreous surgery in patients undergoing a vitrectomy, ${ }^{19}$ as shown in Fig. 3. These patients received $0.4 \%$ ketorolac 4 times per day before the vitectomy. ${ }^{19}$ Levels of ketorolac following intracameral dosing are in excess of those needed for a greater than $90 \%$ inhibition of both COX-1 and COX-2. However, after topical dosing with ketorolac, levels in the vitreous are insufficient to inhibit COX-1 or COX-2. ${ }^{18}$ 


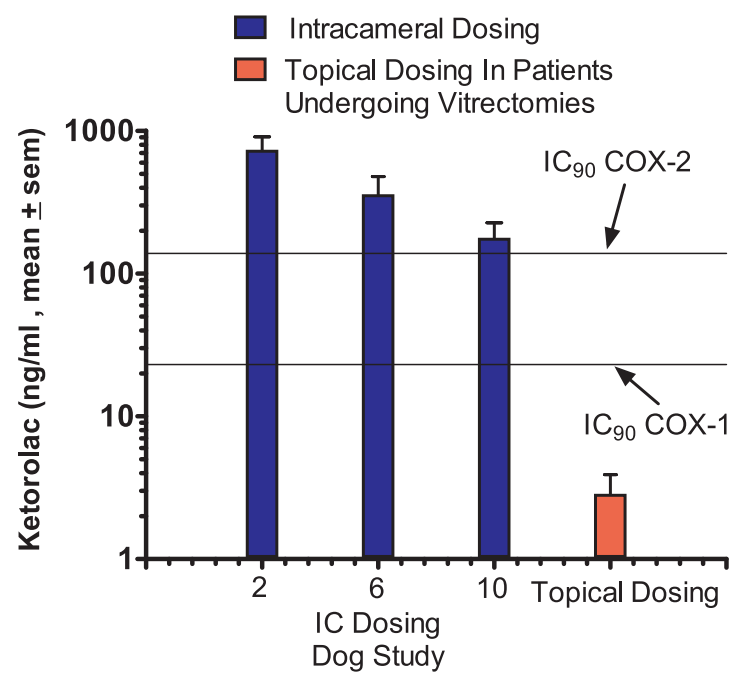

FIG. 3. Vitreous concentrations of ketorolac following dosing during lens replacement surgery in dogs and comparison with concentrations achieved by topical dosing. This figure shows ketorolac concentrations in the vitreous after dosing with $0.008 \%$ phenylephrine and $0.00024 \%$ ketorolac in irrigation solution during lens replacement surgery in dogs. Topical dosing 4 times with $0.4 \%$ ketorolac 3 days before vitrectomies did not achieve concentrations in the vitreous to significantly inhibit COX-1 or COX-2, ${ }^{19}$ suggesting that beneficial effects of ketorolac in patients in preventing cystoid macular edema are likely due to its effects in the anterior segment. These findings in this study were also extended to other NSAIDs, including bromfenac and nepafenac (amfenac). None of these drugs achieved inhibition exceeding $50 \%$ of $\mathrm{PGE}_{2}$ concentrations in the published studies ${ }^{19}$ (results not shown). NSAIDs, nonsteroidal anti-inflammatory drugs.

\section{Discussion}

Suitable methods for estimating the total dose received by ocular irrigation solutions were not found in the literature. Yet, this information is needed to compare this method with topical dosing and to determine possible systemic exposure. This article describes 1 method for partially achieving this objective.

In this study, the total estimated dose of ketorolac given via phenylephrine and ketorolac injection 1\%/0.3\% (OMIDRIA) diluted in irrigation solution and administered intracamerally during surgery provides considerably higher concentrations in target ocular tissues where needed than topical dosing.

Although topical drug administration does provide some delivery of drug to the anterior segment, much of it is lost during lens replacement surgery ${ }^{14}$ as it is likely displaced during cataract surgery by viscoelastic material and irrigation solutions, and furthermore, it does not provide effective concentrations to the posterior segment. ${ }^{20}$ The presence of ketorolac in the aqueous during and immediately after cataract surgery is critical due to its contact with tissues such as iris/ ciliary body that generate the release of the inflammatory prostaglandin $\mathrm{PGE}_{2} \cdot{ }^{21-22}$ It is possible that treatment with topical NSAIDs before surgery may provide adequate levels in some tissues despite the loss in the aqueous, but it also seems likely that ocular tissues in direct contact with the aqueous would experience a considerable loss of NSAIDs. Thus, the topically delivered ketorolac present in the iris/ciliary body would be anticipated to decline rapidly as the ketorolac is in equilibrium with that of the aqueous concentration.
The question can be raised that if other NSAIDs suffer the same fate as ketorolac following topical administration with cataract surgery (ie, are washed out), then how do these drugs inhibit the miotic response associated with surgery? An inhibition of the miotic response to lens surgery by ketorolac, bromfenac, and nepafenac (amfenac) has been reported in several studies. ${ }^{23-25}$ A possible explanation is that the inhibition of prostaglandins is not the mechanism responsible for the antimiotic effect. ${ }^{26}$ In this publication ${ }^{26}$ the conclusion was that the mechanism of action of NSAIDs in inhibiting the miotic effect induced by surgery is unknown.

In addition, ketorolac, bromfenac, and nepafenac (amfenac-the active metabolite) had concentrations in vitreous ${ }^{19}$ below what would result in significant inhibition of COX-1 or COX-2. Thus, the likely mechanism by which NSAIDS prevent cystoid macular edema would be that they inhibit prostaglandin formation in the anterior chamber, which limits their availability to reach the retina.

Other studies have been conducted with intracameral dosing of ketorolac using a fixed amount by direct injection. A direct comparison can be made for vitreous concentrations as reported. ${ }^{27}$ This study conducted in rabbits reported a vitreous concentration of $0.163 \pm 0.04 \mu \mathrm{g} / \mathrm{mL}$ following the intracameral dosing of $250 \mu \mathrm{g} / 0.05 \mathrm{~mL}$ within $2 \mathrm{~h}$. This represents $0.065 \%$ of the administered dose $(250 \mu \mathrm{g})$. In the present study, the percent of estimated total initial dose was $13.5 \%$ in the vitreous at $2 \mathrm{~h}$ postoperatively. The lower amount in the vitreous in the rabbit study may represent species differences (ie, rabbits vs. dogs) or other factors such as concentration of the injected material throughout the eye. Perhaps using a diluted drug in an irrigation solution enhances the surface area of absorption to the back of the eye.

It should be recognized that the aqueous humor in the dog (Table 1) is approximately twice that of human aqueous. This suggests that the dog aqueous would potentially hold twice the total amount of drug versus humans, assuming equal concentrations. Prevention of inflammation and the development of cystoid macular edema following cataract surgery may require adequate anti-inflammatory drug concentrations in both the anterior and posterior. ${ }^{28-30}$

With respect to the anterior segment, there is a constitutive expression of both COX-1 and COX-2 in the normal human eyes with localization in the ciliary body and iris. ${ }^{22}$ This finding makes it critically important that adequate levels of NSAIDs be present in the human aqueous that surrounds these tissues during the surgical procedure. Furthermore, there are no enzymatic mechanisms for removal of $\mathrm{PGE}_{2}$ resulting from the activity of COX-1 and COX-2 in the normal eye. $\mathrm{PGE}_{2}$ is only removed by a specific transporter $^{31}$ and also diffuses to the back of the eye where it may play a key role in the development of cystoid macular edema. This is particularly true during lens implant surgery when the contents of the lens capsule and anterior chamber are displaced by irrigation solutions or viscous substances to maintain the shape of the eye during surgery. ${ }^{3}$ These procedures remove much of the topically administered drugs from the anterior segment. ${ }^{14}$ This is critical because NSAIDs prevent the formation of inflammatory prostaglandins originating from the iris and surrounding tissues. ${ }^{22}$

These results suggest that the beneficial effects of topical NSAIDs in the inhibition of cystoid macular edema result from the inhibition of $\mathrm{PGE}_{2}$ formation in other tissues anterior to the posterior segment such as the iris/ciliary body. 


\section{Conclusions}

The intracameral administration of diluted phenylephrine and ketorolac $1 \% / 0.3 \%$ in a dog study was found to achieve therapeutic levels of ketorolac during surgery in both the aqueous and vitreous. The therapeutic drug levels were maintained for at least $10 \mathrm{~h}$ after surgery.

In contrast, topical dosing with NSAIDs does not provide sufficient aqueous prostaglandin-inhibiting concentrations during or after surgery at the intraocular structures where they are needed most-in target tissues such as the iris and ciliary body. Furthermore, topical dosing does not provide therapeutic NSAID levels in the posterior segment as measured by vitreous drug levels of ketorolac.

This study underscores the need to have pre-emptive antiinflammatory drug activity present throughout the surgical procedure and during the early postoperative period (ie, after the surgical insult has been completed). These findings are consistent with other published studies.

Based on animal studies and clinical data, ${ }^{32,33}$ phenylephrine/ketorolac $1 \%$ and $0.3 \%$ injection delivered during surgery as an irrigation solution may preclude the need for topically administered pre- and postoperative NSAIDs.

\section{Author Disclosure Statement}

Consultant to Omeros Corporation, Seattle, WA; support from unrestricted grant for research, from Omeros.

\section{References}

1. Linebarger, E.J., Hardten, D.R., Shah, G.K., and Lindstrom, R.L. Phacoemulsification and modern cataract surgery. Surv. Ophthalmol. 44:123-147, 1999.

2. Solomon, R., and Donnenfield, E.J. Recent advances and future frontiers in treating age-related cataracts. JAMA. 290:248-251, 2016.

3. Praveen, M.R., Vasavada, V.A., and Vasavada, A.R. Microcoaxial, bimanual and torsional phacoemulsification, p. 10241045. In: Chaudhuri, Z. and Vanathi, M., eds. Postgraduate Ophthalmology, volume 1. New Delhi, India: JaypeeHighlights Medical Publishers, Inc.; 2012; p. 1024-1034.

4. Donnenfield, E., Perry, H, Wittpenn, J., et al. Preoperative ketorolac tromethamine $0.4 \%$ in phacoemulsification outcomes: pharmacokinetic-response curve. J. Cataract Refract. Surg. 32:1472-1482, 2006.

5. Bucci, F.A., and Waterbury, L.D. Pharmacokinetics and pharmacodynamics of nepafenac, amfenac, ketorolac, and bromfenac. J. Cataract Refract. Surg. 34:1226-1227, 2008.

6. Wittpenn, J.R., Silverstein, S., Heier, J., et al. A randomized, masked comparison of topical $0.4 \%$ ketorolac plus steroid vs steroid alone in low-risk cataract surgery patients. Am. J. Ophthalmol. 146:554-560, 2008.

7. Waterbury, L.D. An alternative to topical dosing to deliver drugs to target tissues. J. Ocul. Pharmacol. Ther. 33:3-4, 2017.

8. Ben Simon, G.J., Kenet, G., and Spierer, A. Fibrinoid reaction after lens extraction in rabbit eyes. J. Cataract $R e$ fract. Surg. 38:890-893, 2012.

9. Shibuya, K., Tomohiro, M., Sasaki, S., and Otake, S. Characteristics of structures and lesions of the eye in laboratory animals used in toxicology studies. J. Toxicol. Pathol. 28:181-188, 2015.

10. Wilkie, D.A., and Colitz, C.M.H. Surgery of the lens. In: Gelatt, K.N., Gilger, B.C., and Kern, T.J., eds. Veterinary
Ophthalmology. 5th ed. Hoboken: Wiley-Blackwell; 2013; p. 1234-1253.

11. Omidria ${ }^{\circledR}$ (phenylephrine and ketorolac) $1 \% / 0.3 \%$ Package Insert, Omeros Corporation, Seattle, WA. Available at www .omidria.com/wp-content/uploads/OMIDRIA-PrescribingInformation.PDF (accessed December 23, 2016).

12. Wamberg, S., Sandgaard, N.C.F., and Bie, P. Simultaneous determination of total body water and plasma volume in conscious dogs by the indicator dilution principle. J. Nutr. 132:1711S-1713S, 2002.

13. Waterbury, L.D., Silliman, D., and Jolas, T. Comparison of cyclooxygenase inhibitory activity and anti-inflammatory effects of ketorolac tromethamine and bromfenac sodium. Curr. Med. Res. Opin. 22:1134-1140, 2006.

14. Katsev, D.A., et al. Intracameral ketorolac concentration after topical ketorolac administration before cataract surgery, Abstract Number 11161, ASCRS Posters, 2015, Source URL: Available at www://www.ascrs.org/node/ 22493 (accessed November 30, 2017).

15. Hornung, R.W., and Reed, L.D. Estimation of average concentration in the presence of nondetectable values. Appl. Occup. Environ. Health Hyg. 5:46-51, 1990.

16. Acular ${ }^{\mathrm{TM}}$ (ketorolac tromethamine ophthalmic solution) $0.5 \%$ Package Insert, Allergan Corporation, Irvine, CA. Available at PDF www.allergan.com/assets/pdf/acular_pi (accessed April 18, 2017).

17. Bucci, F.A., and Waterbury, L.D. A randomized comparison of to-aqueous penetration of ketorolac $0.45 \%$. bromfenac $0.09 \%$ and nepafenac $0.1 \%$ in cataract patients undergoing phacoemulsification. Curr. Med. Res. Opin. 27: 2235-2239, 2011.

18. Bucci, F.A., and Waterbury, L.D. Aqueous prostaglandin $\mathrm{E}_{2}$ of cataract patients at trough ketorolac and bromfenac levels after 2 days dosing. Adv. Ther. 26:645-650, 2009.

19. Heier, J.S., Awh, C.C., Busbee B.G., et al. Vitreous nonsteroidal anti-inflammatory concentrations and prostaglandin $\mathrm{E}_{2}$ levels in vitrectomy patients treated with ketorolac $0.4 \%$, bromfenac $0.09 \%$ and nepafenac $0.1 \%$. Retina 29 : 1310-1313, 2009.

20. Maurice, D.M. Drug delivery to the posterior segment from drops. Surv. Ophthalmol. 47:S41-S52, 2002.

21. Nelson, E.L. Prostaglandins and inflammation in the eye. Mod. Prob. Ophthalmol. 16:125-130, 1976.

22. Maihofner, C., Schlotzer-Schrehardt, U., Guhring, H., et al., Expession of cyclooxygenase- 1 and -2 in normal and glaucomatous human eyes. Invest. Ophthalmol. Vis. Sci. 42: 2616-2624, 2001.

23. Abelson, M.B., and Sloan, J. Nonsteroidal anti-inflammatory drugs. Current ophthalmic therapy. J. Fla. Med. Assoc. 81: 261-263, 1994.

24. Keates, R.H., and McGowan, K.A. Clinical trials of flurbiprofen to maintain pupillary dilation during cataract surgery. Ann. Ophthalmol. 16: 919-921, 1984.

25. Cervantes-Coste, G., Sanchez-Castro, Y., Orozco-Carroll, M., Mendoza-Schuster, E., and Velasco-Barona, C. Inhibition of surgically-induced miosis and prevention of postoperative macular with nepafenac. Clin. Ophthalmol. 3 : 219-226, 2009.

26. Camras, C.B., and Miranda, O.C. The putative role of prostaglandins in surgical miosis. In: Bito, L.Z., and Stjernschantz, J., eds. The Ocular Effects of Prostaglandins and Other Eicosanoids. Prog. Clin. Biol. Res. 312:197210, 1989.

27. Wang, M., Liu, W., Qingjun, Z., et al. Pharmacokinetic comparison of ketorolac after intracameral, intravitreal, and 
suprachoroidal administration in rabbits. Retina 32:21582164, 2012.

28. Patel, A., Cholkar, K., Agrahari, V., and Mitra, A.K. Ocular drugs delivery systems: an overview. World J. Pharmacol. 2:47-64, 2013.

29. Bansal, P., Garg, S., Sharma, Y., and Venkatesh, P. Posterior segment drug delivery devices: current and novel therapies in development. J. Ocul. Pharmacol. Ther. 32: 135-144, 2016.

30. Geroski, D.H., and Edelhauser, H.F. Drug delivery for posterior segment eye disease, Invest. Ophthalmol. Vis. Sci. 41:961-964, 2000.

31. Schuster, V.L., Lu, R., and Coca-Prados, M. The prostaglandin transporter is widely expressed in ocular tissues. Surv. Ophthalmol. 41:S41-S45, 1997.

32. Hovanesian, J.A., Sheppard, J.D., Trattler, W.B., et al. Intracameral phenylephrine and ketorolac during cataract surgery to maintain intraoperative mydriasis and reduce postoperative pain: integrated results from 2 pivotal phase 3 studies. J. Cataract Refract. Surg. 41:2060-2068, 2015.

33. Gonzalez-Salinas, R., Guarnieri, A., Guirao Navarro, M.C., and Saenz-de-Viteri, M. Patient considerations in cataract surgery-the role of combined therapy using phenylephrine and ketorolac. Patient Prefer. Adherence. 10:1795-1801, 2016.

Received: April 18, 2017 Accepted: November 3, 2017

Address correspondence to: Dr. L. David Waterbury Raven Biosolutions LLC P.O. Box 7001 San Carlos, CA 94070

E-mail: davidwinca@hotmail.com 